\title{
The Prevalence of Sperm Parameters for Infertile Males in Thi-Qar City
}

\author{
Sumeya Ghanawy AL-Najjar \\ College of Medicine, University of Thi-Qar, Iraq
}

\begin{abstract}
Objective Male infertility is a term in which the male is not capable to attain pregnancy in a female. It occurs due to a lack of semen and low-quality semen. Semen Quality is referred to as a surrogate measure of male fecundity. This study aims to assess the frequency of sperm factors in infertile men in Thi-Qar City. Materials and Methods: This study involved an infertile couple, seminal fluid analysis (SFA) was done to evaluate male factors. Males with normal seminal fluid parameters were excluded. Regarding male, SFA was examined according to WHO 2010. Information such as age, duration of infertility and type of infertility were taken Results Among the percentage of abnormal sperm parameters for infertile couples in which the largest percentage was for asthenozoospermia that represent $66.70 \%$ of all infertile males. The second sperm abnormality is $12.13 \%$ for oligoasthenozoospermia. Asthenoteratozoospermia and oligoasthenoteratozoospermia have the same percentage (4.4). Azoospermia represents $6.7 \%$ while the lower percentage for teratozoospermia. Conclusions largest percentage was for asthenozoospermia that represents $66.70 \%$ of all infertile males .
\end{abstract}

Keywords: Seminal fluid analysis (SFA), sperm parameters

\section{Introduction}

Infertility is a different type of medical care as it relies on both male and female. Infertility is a unique medical condition because it involves a couple, rather than a single individual. In this condition, a couple fails to conceive after 1 year of intercourse without the usage of contraception in females less than the age of 35 years; and after the duration of 6 months of intercourse without the usage of contraception in females less than the age of 35 years and older (clinical definition) ${ }^{[1]}$. This is a very disturbing medical condition as the couple cannot have children if they are suffering from infertility. This further causes depression, psychological distress, and low self-esteem in the couple ${ }^{[2,3]}$.

Types of male infertility

1. Asthenozoospermia

This term is described as the total sperm motility

\section{Corresponding email: Sumeya Ghanawy AL-Najjar \\ dr.basim_moter@yahoo.com}

(non-progressive and progressive), non-progressive morality is less than 40 percent and progressive motility is less than 32 percent. ${ }^{[4)]}$

\section{Oligozoospermia}

A few months ago, the World Health Organization reevaluated the sperm criteria and announced a lower reference point which is less than $15 \mathrm{M}$ sperm/Ml. (WHO 2010), [4]

\section{Azoospermia}

This term is described as the full absence of sperms from a minimum of 2 individual samples of centrifuged semen ${ }^{[4]}$.

\section{Teratozoospermia}

Teratozoospermia; normal sperm morphology is $<4 \%$ Kruger strict criteria ${ }^{[4]}$

\section{Male infertility}

There is a common misunderstanding that the female is responsible for infertility but, it has to be understood that male is equally responsible for this severe medical 
condition $^{[5]}$

\section{Materials and Method}

The study was carried out at infertility unit in Thi Qar city patient. From February 2015 to July 2017. This study involved an infertile couple, SFA was done to evaluate malefactors. Males with normal seminal fluid parameters were excluded. Regarding male, SFA was examined according to WHO 2010. Information such as age, duration of infertility and type of infertility were taken

Table 1: Normal values of semen variables ${ }^{[4]}$

\section{Seminal fluid analysis}

The seminal fluid sample was taken in a clean, sterile, and dry disposable Petri-dish after three to five days of sexual absence. This was done by masturbation in a quiet room near the laboratory of semen analysis. The dish was a label with the name of the male, his age, sexual intercourse absence period, and the exact time of sperms collection. The sample was liquified using an incubator at the temperature of $37^{\circ} \mathrm{C}$ for half an hour. It was then mixed and analyzed by microscopic and macroscopic tests. To note the results of seminal fluid analysis, the standard form of (WHO 2010) was used (Table 1).

\begin{tabular}{|c|c|c|}
\hline \multicolumn{2}{|c|}{ Sperm parameters } & $\begin{array}{l}\text { WHO } \\
\text { Criteria }\end{array}$ \\
\hline \multicolumn{2}{|c|}{ Sperm concentration millions $/ \mathrm{mL}$} & $15 \times 106$ spermatozoa $/ \mathrm{mL}$ or more \\
\hline \multicolumn{2}{|c|}{ Total sperm motility ( $\%$ ) } & $>40 \%$ \\
\hline \multirow{3}{*}{$\begin{array}{l}\text { Sperm } \\
\text { Grade } \\
\text { Activity }\end{array}$} & Progressive motility ( \% ) & $>32 \%$ \\
\hline & Non Progressive motility ( $\%$ ) & \\
\hline & Immotile sperm $(\%)$ & \\
\hline \multicolumn{2}{|c|}{ Normal sperm morphology (\%) } & $>30 \% *$ \\
\hline
\end{tabular}

\section{Results}

Figure 1 shows the percentage of abnormal sperm parameters for infertile couples in which the largest percentage was for asthenozoospermia that represent $66.70 \%$ of all infertile males. The second sperm abnormality is $12.13 \%$ for oligoasthenozoospermia Asthenoteratozoospermia and oligoasthenoteratozoospermia have a same percentage (4.4). Azoospermia represents 6.7\% while the lower percentage for teratozoospermia.

In our study table, 2 show the effect of male infertility duration on sperm parameters. Regarding sperm concentration there is a significant decline at 5-10years, also there is a significant decline in sperm morphology when duration more than 10 years.

Table 3 discuss the effect of male infertility type in sperm parameters whether primary or secondary. There is no significant difference between primary and secondary types for all sperm parameters (sperm concentration, motility, and morphology).

Table 4 shows the distribution into primary and secondary fertility among infertile couples, $60 \%$ of them with primary infertility and $40 \%$ with secondary infertility. 


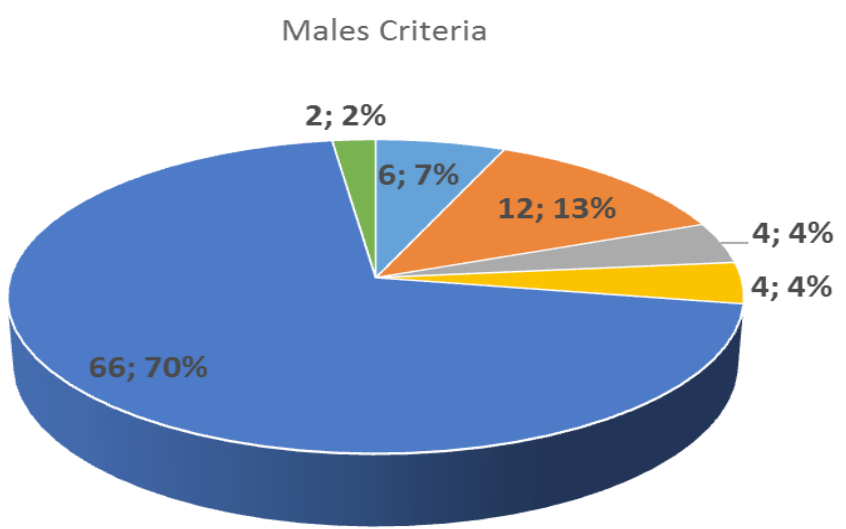

- Azospermia
- oligo astheno teratospermia
- astheno spermia

- oligo astheno spermia

w astheno terato spermia

- Terato spermia

Figure 1. sperm parameters

Table2: Effect of male infertility duration on sperm parameters.

\begin{tabular}{|l|l|l|l|}
\hline Infertility duration Parameters & $\mathbf{1 - 5}$ years & $\mathbf{5 - 1 0}$ years & $\geq \mathbf{1 0}$ years \\
\hline Sperm concentration & $44.417 \pm 4.10 \mathrm{a}$ & $38.375 \pm 4.92 \mathrm{~b}$ & $46.944 \pm 5.74 \mathrm{a}$ \\
\hline Progressive motility \% & $11.763 \pm 2.21 \mathrm{a}$ & $8.081 \pm 2.58 \mathrm{a}$ & $12.300 \pm 3.42 \mathrm{a}$ \\
\hline Non-progressive motility \% & $28.383 \pm 2.69 \mathrm{a}$ & $29.425 \pm 3.23 \mathrm{a}$ & $32.178 \pm 4.17 \mathrm{a}$ \\
\hline Immotile sperm & $43.615 \pm 2.79 \mathrm{~b}$ & $44.813 \pm 4.38 \mathrm{~b}$ & $52.439 \pm 5.34 \mathrm{a}$ \\
\hline sperm morphology \% & $52.944 \pm 3.67 \mathrm{a}$ & $43.188 \pm 3.64 \mathrm{~b}$ & $45.468 \pm 2.47 \mathrm{~b}$ \\
\hline
\end{tabular}

- $\quad$ Means with similar letters are nonsignificant different $(\mathrm{P}>0.05)$.

Means with different letters are significant deferments ( $\mathrm{P} \leq 0.05)$.

Table3: Effect of male infertility type in sperm parameters.

\begin{tabular}{|l|l|l|}
\hline Age groups Parameters & Primary & Secondary \\
\hline Sperm concentration & $42.459 \pm 3.59 \mathrm{a}$ & $43.649 \pm 4.41 \mathrm{a}$ \\
\hline Progressive motility \% & $10.298 \pm 1.80 \mathrm{a}$ & $11.254 \pm 2.69 \mathrm{a}$ \\
\hline Non progressive motility \% & $28.984 \pm 2.38 \mathrm{a}$ & $30.141 \pm 2.93 \mathrm{a}$ \\
\hline Immotile sperm & $44.633 \pm 3.11 \mathrm{a}$ & $47.265 \pm 2.84 \mathrm{a}$ \\
\hline sperm morphology \% & $44.567 \pm 2.30 \mathrm{a}$ & $48.595 \pm 3.05 \mathrm{a}$ \\
\hline
\end{tabular}

- Means with similar letters are non-significant different $(\mathrm{P}>0.05)$.

Means with different letters are significant deferments ( $\mathrm{P} \leq 0.05)$. 
Table 4: Distribution into primary and secondary fertility among infertile couples.

\begin{tabular}{|l|l|l|}
\hline Infertility & Frequency & Percentage (\%) \\
\hline Primary & 60 & $60 \%$ \\
\hline Secondary & 40 & $40 \%$ \\
\hline Total & 100 & $100 \%$ \\
\hline
\end{tabular}

\section{Discussion}

Moreover, the sperm parameters correlate negatively with increased period of infertility ${ }^{[7]}$. These findings are in agreement with the results of the present study that the male patients with duration of infertility (1-5) years were with the lowest percentage of sperm motility.

The results of this study showed that primary infertility $(60 \%)$ was more than secondary infertility (40\%) as it is obvious from table 4. But, in men having primary infertility, genetic and chromosomal factors have a vital role in the presence of primary infertility than secondary infertility ${ }^{[8]}$.

A retrospective study, conducted between 1992 to 1999 highlights the occurrence of asthenozoospermia as $18.71 \%$ and for asthenozoospermia, it was $63.13 \%$, linked with oligo- or teratozoospermia. So, 81.84 percent of the investigated samples indicated altered motility. ${ }^{[9]}$

In research conducted in Nepal, $20 \%$ of the couples indicated semen abnormality. $47 \%$ indicated oligospermia while $39 \%$ indicated azoospermia. Moreover, $14 \%$ of males had asthenormia. ${ }^{[10]}$.

Socioeconomic, environmental, and nutritional aspects are responsible for compromising the health of the male reproductive system [11]. Chemotherapy, radiation, and surgery may have an impact on spermatogenesis [12]. A research conducted in Senegal to check this abnormality, oligoasthenoteratonecrozoospermia showed the highest percentage that is 20.2 percent while azoospermia showed 14.5 percent and asthenonecrozoospermia and astheno-necrozoospermia both showed the occurrence as $10.3 \%$ [13]. However, Pontonnier indicates that oligoasthenoteratozoospermia is the chief abnormality that is usually found in the general population and particularly in varicocele [14].

Conflict of Interest: The author has no disclosures to report.

\section{Source of Funding: Self.}

Ethical Clearance: Not required.

\section{References}

1. American Society for Reproductive Medicine (ASRM): A Practice Committee Report. Definitions of infertility and recurrent pregnancy loss. Fertil Steril 2008; 90:560.

2. Chachamovich JR, Chachamovich E, Ezer H, et al. Investigating quality of life and health-related quality of life in infertility: a systematic review. J Psychosom Obstet Gynaecol. 2010; 31:101-110.

3. Cui W. Mother or nothing: the agony of infertility. Bull World Health Organ. 2010; 88:881-882.

4. World Health Organization. WHO Laboratory Manual for the Examination and Processing of Human Semen, 5thed. Geneva: World Health Organization; 2010.

5. Esteves SC, Miyaoka R, Agarwal A. An update on the clinical assessment of the infertile male. Andro Hum Reprod. 2011; 66(4):691-700.

6. World Health Organization. WHO Laboratory Manual for the Examination of Human Semen and Sperm-cervical Mucus Interaction, 4th ed. Cambridge: Cambridge University Press 1999.

7. Chehval MJ and Purcell MH. Deterioration of semen parameters over time in men with untreated varicocele: evidence of progressive testicular damage. Fertil Steril.1992;57:174-7.

8. Madoro MR, Kirk CL, Chuang WW, et al. Genes and male infertility: What can go wrong? J Androl 2003; 24: 765-769.

9. S M Curi ,Julia Ariagno ,Patricia Chenlo, Gabriela $\mathrm{R}$ Mendeluk. Analysis of a large population, Article in Archives of Andrology.2003; 49(5):343-9.

10. Pant Pr,Department of Obstetrics and Gynaecology, Tribhuvan University Teaching Hospital, Kathmandu, Nepal. Abnormal Semen Parameters among Men in Infertile Couples. NJOG 2013 ; $8(1): 53-55$.

11. Mathur PP, D' Cruz SC. Effect of environmental contaminants on testicular function.Asian J Androl. 2011;13(4):585-91.

12. Holoch $\mathrm{P}$, Wald M. Current options for preservation 

of fertility in the male. Fertil Steril. 2011;96(2):28690.

13. Mama Sy Diallo1*, Abdoulaye Séga Diallo1, Pyrrhus Fotso1, Yoro Diallo2, Babacar Diao3, Oumar Faye1. Semen Abnormality Patterns and
Parameters in Male Partners of Infertile Couples in Dakar (Senegal) Journal of Urology, 2015, 5, 155160.

14. Pontonnier, F. and Bujan, L. Comment Reconnaître et classer une infécondité masculine. Rev Prat, 1993; 43, 941-9 